\title{
Information Strategies for Open Government in Europe: EU Regions Opening Up the Data on Structural Funds
}

\author{
Luigi Reggi $^{1,2, *}$ and Chiara Assunta Ricci ${ }^{2}$ \\ ${ }^{1}$ Ministry for Economic Development, Department for the Development and the Economic \\ Cohesion, Via Sicilia 162, 00187, Rome, Italy \\ ${ }^{2}$ University "La Sapienza", Faculty of Economics, Department of Public Economics, Via del \\ Castro Laurenziano 9, 00161, Rome, Italy \\ luigi.reggi@gmail.com; chiaraaricci@yahoo.it
}

\begin{abstract}
This empirical study explores the information-based strategies that EU Regions and Member States are implementing when publishing public data on the web. Cohesion Policy and its Structural Funds, which involve all EU Regions and Member States, are the ideal context to verify the presence of different approaches to the publication of government data. Therefore, 434 datasets on beneficiaries of EU Structural Funds are analysed with multivariate statistical techniques and classified into three clusters according to their characteristics. Two pro-active information strategies are identified, which are consistent with the theoretical framework based on the complementary principles of "stewardship" and "usefulness". The analysis of current practice also reveals that there is still much to be done in order to find the right balance between these two principles.
\end{abstract}

Keywords: Open Government, Transparency, Government Information Strategies, Structural Funds.

\section{Introduction}

The new European e-Government Action Plan 2011-2015 [13] dedicates specific actions to Open Government and identifies two main sources of potential benefits: transparency and data re-use. While the latter is focused on the creation of value by combining "raw data" from different sources and making "mash-ups" and new applications [5, 16, 2], the former is a positive effect of opening up data and information on government decision making, such as laws and regulations, policies and finance [4].

These topics are at the centre of the European Directive on the re-use of Public Sector Information (PSI), adopted at the end of 2003 and reviewed in 2009, which have introduced a common legislative framework regulating how public sector bodies should make their information available for re-use in order to remove barriers such as discriminatory practices and monopoly markets by harmonizing the regime for the reuse of PSI, broadly defined as any information held by public sector organization.

* The views expressed in this article are those of the author and, in particular, do not necessarily reflect those of the Ministry of Economic Development. 
According to the general principle of the Directive (Art. 3), "Member States shall ensure that, where the re-use of documents held by public sector bodies is allowed, these documents shall be re-usable for commercial or non-commercial purposes in accordance with the conditions set out in Chapters III and IV. Where possible, documents shall be made available through electronic means".

By now, all 27 EU Member States have implemented the PSI Directive into their national legal orders but considerable differences still persist in actual practices among public actors.

In particular, once government decides to make available its data on the web, the detail level of the information provided, the quality of data and the way it is provided are crucial elements that must be taken into account to ensure real transparency and re-use of the PSI.

The literature on public use of government information can offer valuable insights.

First, it is essential to determine how much the government will engage in valueadded services itself and how much it will leave to private providers [9]. Governmentproduced reports, charts, and analyses can be very valuable [1] but "it is essential to also publish the underlying data itself in a computer-friendly format that makes it easy for the vibrant community of civic technologists to make and share a broad range of tools for public engagement" [16].

Secondly, since the community of information users is not homogeneous [4], more complete stakeholder analysis could lead to better understanding of users' needs and help identify which kinds of information content or formats generate different kinds of value for different communities of interest [9].

Dawes [8] proposes a framework based on two complementary information policy principles that need equal consideration: stewardship and usefulness. The first principle recognizes government information as a public good and focuses on assuring accuracy, validity, security, management and preservation of public information. In other words, it makes information "fit for use". The second principle focuses on increasing public value by enhancing public access to government information and making possible the re-use of information for new purposes. Dawes [8] also offers some examples by assessing the proposals that had been posted on Data.gov online dialog by April 21, 2010: "create or improve metadata", "improve data management", "adopt data standard and standard formats" are classified into the "stewardship proposals", while "provide easy-to-use basic features", "improve and enhance searching and display" are classified into the "usefulness proposals."

EU Structural Funds represents an ideal context for indentifying information-based strategies. On one hand, all Member States and EU regions are involved and share common rules and regulations, which makes data perfectly comparable. On the other hand, the regulations focus only on a minimum set of requirements for publishing data on the web, which leaves room for improvement in terms of detail, quality, access and visualization.

Therefore, this empirical study examines the information-based strategies that European governments are pursuing when publishing their data on the web. The paper is organized as follows. First, we introduce the EU Regional policy and the efforts that are being made to foster transparency in the use of Structural Funds. Next we describe the data we have collected on the lists of beneficiaries of the Funds, then we 
present the results of an empirical analysis aimed at identifying the underlying information strategies. The last section is dedicated to the discussion of the characteristics of the three strategies revealed and to the final conclusions.

\section{Regional Policy and Transparency}

European Regional Policy (otherwise named European Cohesion Policy) "aims to promote harmonious development of the Union and its regions by reducing regional disparities" (Article 174 of the Treaty).

The policy "underpins the growth model of the Europe 2020 strategy including the need to respond to societal and employment challenges all Member States and regions face. [...] The multilevel governance system for the policy helps to make the EU more visible to its citizens" [12]

Regional policy is implemented mostly thanks to two Structural funds, namely the European Regional Development Fund (ERDF) and the European Social Fund (ESF). ERDF is aimed at leveling economic differences among regions and it finances, for example, initiatives for research and innovation, local development and employment, infrastructure, and protection and improvement of the environment. ESF was established to improve the quality and accessibility of jobs and employment opportunities within the European Union. The amount of Community resources dedicated to Regional Policy in 2007-13 is EUR 347 billion [11]; in addition to the Community financing, substantial national and regional budgets are mobilized.

Financial resources are concentrated on the lagging regions that fall under the Convergence objective, with $81.5 \%$ of the investment available. The declared rationale of the Convergence objective is to promote growth-enhancing conditions and factors. Outside the Convergence regions, the Regional Competitiveness and Employment objective (Competitiveness) aims at strengthening competitiveness and attractiveness, as well as employment, especially through innovation and the promotion of the knowledge society. The European Territorial Cooperation objective (Cooperation) strengthens cross-border co-operation through joint local and regional initiatives, trans-national co-operation and interregional co-operation and exchange of experience.

Structural Funds regulations for the 2007-13 programming period require the Managing Authorities (Member States and Regions managing an Operational Programme financed by Structural Funds) to publish the names of the beneficiaries, the name of the project co-financed with Structural Funds and the corresponding amount of public funding received. In fact, according to Article 69 of the Council Regulation No 1083/2006 of 11 July 2006 and repealing Regulation (No 1260/1999), "the Member States and the Managing Authority for the operational programme shall provide information on and publicize operations and co-financed programmes. The information shall be addressed to European Union citizens and beneficiaries with the aim of highlighting the role of the Community and ensuring that assistance from the Funds is transparent". In particular, Commission Regulation No 1828/2006 of 8 December 2006 (art. 7) states that "the managing authority shall be responsible for organizing the publication, electronically or otherwise, of the list of beneficiaries, the names of the operations and the amount of public funding allocated to the operations". 
In November 2005 the European Commission launched a 'European Transparency Initiative' (ETI). A detailed Guidance Note of 23 April 2008 commits to the Commission the coordinating role of facilitating access to the data available on the websites of the managing authorities and proposes a common standard for the publication of data, so as to enable interested parties to carry out consistent analyses across the EU. A set of minimum information is proposed in an "indicative table for setting the list of beneficiaries of EU funding". This set includes: (a) The name of beneficiaries, (b) the name of the operation, (c) the amount of public funding committed to the operation, (d) the amount of public funding paid to the beneficiary at the end of the operation, (e) the year of final payment, (f) the date of the last update.

\section{Data Collection}

In October 2010, we conducted a web-based survey in order to explore the availability and quality of the lists of projects and beneficiaries of the European Regional Development Fund (ERDF) and the European Social Fund (ESF) published by the managing authorities across Europe. We have taken into account all 434 Programmes included in an official database provided by the DG Regional Policy in June 2009.

Table 1. Characteristics of the lists of beneficiaries of EU Structural Funds

Characteristic of the list of beneficiaries

Name of the project

Name of the beneficiary

Amounts committed to the project

Amounts effectively paid at the end of the project

Amounts co-financed by EU Funds (ERDF, ESF)

Detailed description of the project

Status of the project (active, completed)

Year of allocation

Action of the Operational Programme

Territory where the project impacts (at NUTS3 level territory or higher detail)

Format of the dataset: PDF

Format of the dataset: HTML

Format of the dataset: Microsoft Excel or CSV

Description of data and metadata

Description of data in English

Map for data visualization

Research mask

Number of clicks to access data $(0=3$ or more, $1=$ less Clicks than 3)
Pdf

$260(60 \%)$

$99(23 \%)$

$136(31 \%)$

data_desc $58(13 \%) \quad 58(14 \%)$

english $66(15 \%)$

Map $61(14 \%)$

search

\section{Frequency Frequency \\ (409 OPs with \\ financial data)}

$\begin{array}{lll}\text { project } & 409(94 \%) & 409(100 \%) \\ \text { Benef } & 409(94 \%) & 409(100 \%) \\ \text { tot_funds } & 409(94 \%) & 409(100 \%) \\ \text { paid_out } & 122(28 \%) & 122(30 \%) \\ \text { ue_contr } & 192(44 \%) & 192(47 \%) \\ \text { pr_descr } & 85(20 \%) & 85(21 \%) \\ \text { Status } & 72(17 \%) & 72(18 \%) \\ \text { Year } & 259(60 \%) & 259(63 \%) \\ \text { actions } & 67(15 \%) & 67(16 \%) \\ \text { territory } & 52(12 \%) & 52(13 \%)\end{array}$

$260(64 \%)$

$98(24 \%)$

$66(16 \%)$

$61(15 \%)$

$130(30 \%) \quad 128(31 \%)$

$393(91 \%) \quad 372(91 \%)$ 
Datasets published on the web and containing the lists of beneficiaries and projects co-financed by Structural Funds were identified through a visit to the URIs indicated by the managing authorities and reported in the Inforegio ${ }^{l}$ web site (managed by the DG Regional Policy of the European Commission) or in the web site of the European Social Fund ${ }^{2}$ (managed by the DG Employment). We performed a search in the websites of regional operational programmes and of regional managing authorities when the link was broken or unavailable.

Table 1 shows the characteristics and features of the lists of beneficiaries of EU Structural Funds included in the survey, and their frequency. The characteristics that are not covered either by Structural Funds regulation or by the ETI were chosen after an extensive review of current literature and the latest policy reports on the matter $[15,7,3]$ and the main institutional technical guidelines available on this topic $[17,6]$.

\section{Results}

The first step of our analysis is the application of a Multiple Correspondence Analysis (MCA) to the data collected. As a second step, we have performed a cluster analysis (CA) on the two dimensions considered in order to verify and test the presence of different groups corresponding to different information strategies.

\subsection{Multiple Correspondence Analysis}

Multiple Correspondence Analysis (MCA) is an extension of simple correspondence analysis to more than two categorical variables. The extraction of dimensions in MCA is similar to the identification of components in principal components analysis, or factors in factor analysis. MCA is more commonly used for exploratory, inductive research rather than hypothesis testing and deductive research. This is done by using the dimensions produced by the technique to generate scatter-plots with the scores of the column variables plotted in these dimensions. Variables with similar scores in these dimensions locate close together in these plots to reveal high degrees of association between them in the analyzed dimensions. These associations are also stronger the further the points are from the origin of the plots [14].

Table 2. Revealed dimensions from Multiple Correspondence Analysis

\begin{tabular}{llll}
\hline & Principal inertia & $\begin{array}{l}\text { Percentage } \\
\text { variation }\end{array}$ & $\begin{array}{c}\text { of } \\
\text { total Cumulative percentage of } \\
\text { total variation }\end{array}$ \\
\hline Dimension 1 & 0.0413496 & 60.22 & 60.22 \\
Dimension 2 & 0.0112699 & 16.41 & 76.64 \\
Dimension 3 & 0.0021024 & 3.06 & 79.7 \\
Dimension 4 & 0.00094 & 1.37 & 81.07 \\
Dimension 5 & 0.0000467 & 0.07 & 81.14 \\
Total & 0.0686607 & 100 &
\end{tabular}

\footnotetext{
${ }^{1}$ http://ec.europa.eu/regional_policy/country/commu/beneficiaries/index_en.htm

${ }^{2}$ http://ec.europa.eu/employment_social/esf/discover/article_7093_en.htm
} 
For our analysis, therefore, each characteristic of the list of beneficiaries was coded for both its 'yes' and 'no' presence. The MCA found 5 dimensions in the data, each of which accounted for between $60.2 \%$ and $0.07 \%$ of the total variation in the data (see Table 2). We will consider the first two dimensions, which individually accounted for the largest amount of variation in the data $(76,6 \%)$.

\subsection{Cluster Analysis}

The second step of our analysis is to perform a Cluster Analysis (CA), which uses the first two dimensions revealed by the MCA as input variables. Two different methods of CA have been tested. First, an iterative partitioning method ( $K$-means procedure) has been applied. Secondly, after having identified the main resulting clusters, three distinct hierarchical agglomerative methods have been applied (between groups linkage, within groups linkage, Ward's method), and three different ways to measure the distance between cases have been used (Euclidean, squared Euclidean, and cosine distance) to check the robustness of the results of the $K$-means procedure. Both the clustering algorithms have produced three main clusters.

In order to further test the statistical precision of our classification, we performed an estimation of three logit models, which estimate the strength of the association between the two factors used in the cluster analysis (input variables) and the resulting classification. As showed in Table 3, the estimation of the three logit models support the validity of the results of the cluster analysis (both in terms of significance of the single coefficients and the predictive ability of the models) and is fully consistent with the graphical analysis reported in Fig 1:

- Cluster 1 is characterized by positive values of Dimension 1 and negative values of Dimension 2.

- Cluster 2 is characterized by positive values of Dimension 1 and 2.

- Cluster 3 is only characterized by negative values of Dimension 1, while, as expected, the results for Dimension 2 are not statistically significant.

Table 3. Results of the three logit tests for cluster analysis

\begin{tabular}{lrrr}
\hline & $\begin{array}{l}\text { Cluster 1- } \\
\text { User-centered (\%) }\end{array}$ & $\begin{array}{l}\text { Cluster 2 } \\
\text { Re-user-centered } \\
(\%)\end{array}$ & $\begin{array}{l}\text { Cluster } \\
\text { Regulation-centered } \\
(\%)\end{array}$ \\
\hline Dimension 1 & $1.661488 * * *$ & $8.983535 * * *$ & $-6.939635 * * *$ \\
Dimension 2 & $-3.430431 * * *$ & $10.69435 * * *$ & -0.2407551 \\
Pseudo-R2 & 0.7192 & 0.9525 & 0.7703 \\
Correctly classified & $96.09 \%$ & $99.51 \%$ & $90.71 \%$ \\
$* * *$ Significant at 1\% level. & & &
\end{tabular}

In table 4 is reported the individual contribution of the variables to the first two dimensions considered. The characteristics showing the highest level of contribution to the first dimension are: the presence of a research mask, information on the status of the project and the description of the data. The PDF format is the only variable negatively correlated with the first dimension. As for the second dimension, which could be 
interpreted as a measure of the quality of the data provided, is characterized by the variables regarding the level of information detail (e.g. key financial data as the amount of money effectively paid to the beneficiary; information on the specific action of the Operational Programme, which is useful for example for policy evaluation purposes).

Table 4. Contribution of the characteristics of the lists of beneficiaries to the first two dimensions of the MCA (Pearson correlation)

\begin{tabular}{lll}
\hline Characteristic of the list of beneficiaries & Dimension 1 & Dimension 2 \\
\hline Amounts effectively paid at the end of the project & $0.2654^{* * *}$ & $0.5795^{* * *}$ \\
Amounts co-financed by EU Funds (ERDF, ESF) & $0.1781^{* * *}$ & $-0.5205^{* * *}$ \\
Detailed description of the project & $0.6019^{* * *}$ & $-0.1694^{* * *}$ \\
Status of the project (active, completed) & $0.6682^{* * *}$ & $0.2871^{* * *}$ \\
Year of allocation & $0.0843^{*}$ & $0.3288^{* * *}$ \\
Action of the Operational Programme & $0.4404 * * *$ & $0.4521^{* * *}$ \\
Territory where the project impacts (at NUTS3 level) & $0.5207^{* * *}$ & 0.0321 \\
Format: PDF & $-0.6521 * * *$ & $-0.2156^{* * *}$ \\
Format: HTML & $0.3104 * * *$ & $-0.7365^{* * *}$ \\
Format: Microsoft Excel or CSV & $0.585^{* * *}$ & $0.1027^{* *}$ \\
Description of the data and metadata & $0.6635^{* * *}$ & $0.2993^{* * *}$ \\
Description of the data in English & $0.5875^{* * *}$ & $0.2282^{* * *}$ \\
Map for data visualization & $0.5236^{* * *}$ & $-0.4652^{* * *}$ \\
Research mask & $0.7133^{* * *}$ & $-0.5386^{* * *}$ \\
Number of clicks to access data $(0=3$ or more, 1= less than 3) & $0.1525^{* * *}$ & $-0.3556^{* * *}$ \\
$* * *$ Significant at 1\% level; ** significant at 5\% level; * significant at $10 \%$ level &
\end{tabular}

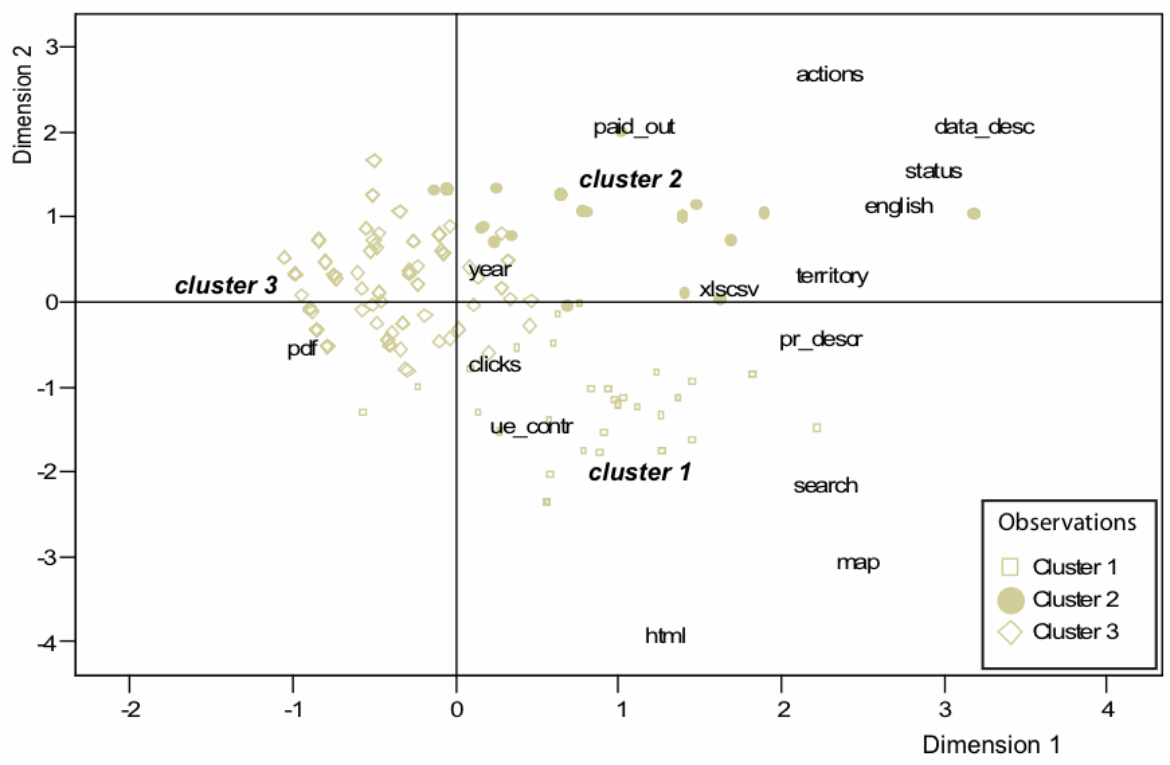

Fig. 1. Identifying three information strategies 
Figure 1 shows the plot of the variables included in the MCA according to their scores in dimensions 1 and 2. As explained earlier, where variables are closely grouped together, they show high levels of association. The location of the variables is related to the individual contribution to the two dimensions considered. The figure also shows the single observations belonging to the three clusters identified through the CA.

The first cluster of variables is found at the bottom-right corner of the plot (Cluster 1). This group of variables shows the administrations' effort to make data understandable by non-technically oriented citizen, clearly represented, and accessible to users. This includes the presence of data visualization tools and on line forms that enhance searching and display. In particular, as table 5 shows, the most common characteristics of the lists of beneficiaries belonging to this cluster are the presence of HTML tables (99\%), research masks (94\%) and maps for geo-referenced data visualization (54\%). On the contrary, while the data is always showed in HTML lists, typically as the result of a search action, only $46 \%$ of the lists are actually downloadable from the website in XLS or CSV formats, which could let the users further elaborate the data by themselves. For convenience, we label this cluster "User centered".

Table 5. Characteristics of the lists of beneficiaries of EU Structural Funds and the three information strategies indentified

\begin{tabular}{|c|c|c|c|c|}
\hline Characteristic of the list of beneficiaries & $\begin{array}{l}\text { Cluster } 1 \\
\text { User- } \\
\text { centered } \\
(\%) \\
\end{array}$ & $\begin{array}{l}\text { Cluster } 2 \\
\text { Re-user- } \\
\text { centered } \\
(\%)\end{array}$ & $\begin{array}{l}\text { Cluster } 3- \\
\text { Regulation- } \\
\text { centered (\%) }\end{array}$ & $\begin{array}{l}\text { Total of } \\
\text { OPs with } \\
\text { financial } \\
\text { data }(\%)\end{array}$ \\
\hline $\begin{array}{l}\text { Amounts effectively paid at the end of the } \\
\text { project }\end{array}$ & 2 & 60 & 30 & 30 \\
\hline $\begin{array}{l}\text { Amounts co-financed by EU Funds (ERDF, } \\
\text { ESF) }\end{array}$ & 80 & 39 & 38 & 47 \\
\hline Detailed description of the project & 45 & 39 & 8 & 21 \\
\hline Status of the project (active, completed) & 12 & 60 & 7 & 18 \\
\hline Year of allocation & 50 & 91 & 60 & 63 \\
\hline Action of the Operational Programme & 23 & 35 & 9 & 16 \\
\hline $\begin{array}{l}\text { Territory where the project impacts (at } \\
\text { NUTS3 level) }\end{array}$ & 1 & 61 & 2 & 13 \\
\hline Format: PDF & 51 & 7 & 85 & 64 \\
\hline Format: HTML & 99 & 3 & 6 & 24 \\
\hline Format: Microsoft Excel or CSV & 46 & 93 & 11 & 33 \\
\hline Description of the data and metadata & 13 & 57 & 2 & 14 \\
\hline Description of the data in English & 17 & 49 & 6 & 16 \\
\hline Map for data visualization & 54 & 20 & 1 & 15 \\
\hline Research mask & 94 & 37 & 9 & 31 \\
\hline $\begin{array}{l}\text { Number of clicks to access data }(0=3 \text { or } \\
\text { more, } 1=\text { less than } 3)\end{array}$ & 99 & 95 & 87 & 91 \\
\hline
\end{tabular}

Another cluster of variables appears at the top-right of the Fig. 1 (Cluster 2). The group is defined by many desirable characteristics aimed at assuring accuracy, validity, security, management, and preservation of information holdings, and therefore related to the principle of "stewardship". 
Distinctive features of this group, as reported in table 5, are: the ability to download the data in a machine-readable format (93\%) - which also enables effective data re-use - plus other characteristics related to data quality, such as the year of allocation of the funding $(91 \%)$, the presence of the territory where the projects impact at NUTS 3 level $(61 \%)$, the description of the data $(57 \%)$, that makes data easier to access, understand and use. We call this cluster "Re-user centered".

A third cluster (Cluster 3) is located at the left of the diagram. This group is associated with low values of Dimension 1 and is characterized by the absence of all the desirable features considered in the survey. In fact, low values of the first dimension can be associated to poor quality of the lists of beneficiaries of Structural Funds. The most common characteristic of this group is indeed the presence of the PDF format $(85 \%)$. The use of PDF format makes the re-use of data dramatically difficult and is at odds with the stewardship principle that demands that government information should be acquired, used, and managed as a resource.

The managing authorities of the programmes belonging to this cluster seem to be more interested in formally meeting the requirements of the regulation than in pursuing real transparency. For this reason we can call this cluster "Regulation centered".

As just reported, our analysis identifies a sort of "non strategy" (cluster 3, "Regulation centered") along with of two pro-active strategies corresponding to two different paths. A first path (cluster 1, "User centered") is consistent with the usefulness principle, while the other (cluster 2, "Re-user centered") is mainly focused on the stewardship principle.

Consequently, the theoretical framework proposed by Dawes [8] seems to be particularly useful to interpret this empirical results and shed some light on the different ways the EU public agencies are dealing with opening up their data on the web.

Moreover, the evidence that these two principles are connected to two statically different clusters suggests that EU agency have much to do in order to find the right balance between the stewardship and the usefulness approach. The two principles are in fact complementary and mutually reinforcing [8].

\section{Conclusions and Policy Implications}

In order to verify the presence of different information strategies that European public agencies are following when opening up their data, we conducted a web-based survey on the quality of the lists of beneficiaries of Structural Funds provided by the EU Regions and Member States responsible for the 434 Operating Programmes of the European Cohesion Policy. This policy represents an ideal context for such an assessment because, on one hand, it involves all EU Regions and Member States with common rules and regulations and, on the other hand, it limits the requirements for publishing the data on beneficiaries to a small set of minimum information. In other words, while the policy is implemented under the same rules across Europe, hundreds of public authorities responsible for managing Structural Funds are free to choose their information strategy when publishing their data on the web. 
In October 2010 we collected data on fifteen variables corresponding to the presence/absence of a set of characteristics which includes not only the requirements of the current regulations plus the recommendations of the European Transparency Initiative, but also other features suggested by the literature and by technical official guidelines.

A multivariate analysis was applied to the data collected. The location of the variables in the MCA plot and the consequent cluster analysis reveal the presence of three information strategies, which are consistent with the most recent literature on this topic and, in particular, with the framework based on the two broad information principles "stewardship" and "usefulness". While a group that we called "Regulation centered" seems interested only in formally meeting the minimum requirements set by the regulations and therefore is publishing the data in PDF format with limited or no further detail, two alternative paths for pro-actively publishing government information on the web are revealed. The first path (cluster 1, "User centered") focuses on data visualization and searching and deals with the usefulness principle, and the second (cluster 2, "Re-user centered") leads to data quality and validity and is consistent with the stewardship principle.

In conclusion, the analysis confirms the robustness of the theoretical framework proposed by Dawes [8]. The desirable features of public datasets that were taken into account in this study tend to aggregate themselves into two groups which are consistent with the two broad principles "stewardship" and "usefulness".

Finding the right balance between these two principles is the key for ensuring data quality while fostering transparency, innovation and the creation of new added-value services. This analysis, which connect the two principles to two statistically different groups of public agencies, demonstrate that there is much to be done in order to finally find this balance.

On the one hand, EU regions following a "user centered" approach must consider not only the needs of the "average user" looking for a single data or cool elaborations, but also the requests of civil society organizations, "civic hacking" initiatives, data journalists, and individual citizens interested in re-using the raw data in order to improve the accountability of the policy, e.g. by facilitating inter-regional comparison, setting up advanced tools for data visualization, doing mash-ups with other sources of territorial information. The lists of projects displayed in hundreds of HTML pages, typically as the results of a search action on the region's website, should be exportable in a single file for further elaboration. Besides, our analysis highlights that the authorities belonging to the "user centered" cluster tend to focus on the presentation aspects while the level of detail and the overall quality of the data provided is relatively low compared to the "stewardship" cluster and therefore should be improved.

On the other hand, the "re-user centered" organizations that make available the data only in XLS or CSV format should consider the differences within and among communities of users in terms of e-skills, and in particular with respect to the ability to analyze the data in a meaningful way (e.g. in a spreadsheet). Therefore, together with the raw data, data in a processed or aggregate form should be provided in order to make it accessible also by non-technically oriented citizen.

As for the "regulation centered" group of public authorities, an improvement of the regulation itself will force these administrations to do better. The desirable 
characteristics of the lists of beneficiaries considered in this paper may help the European Commission and the other authorities involved in Regional Policy to set new and more stringent targets and requirements for the next funding period in terms of quality, openness and completeness. From a technical and organizational point of view, this will not necessarily imply the need for extra budget, major changes in information management or the update of existing software and infrastructures. Actions for raising the awareness among national and local authorities of the benefits that could derive from opening up existing data and information in a re-usable way are considered much more important.

\section{References}

1. Baxandall, P., Wohlschlegel, K.: Following the Money Washington, DC: U.S. PIRG Education Fund (2010),

http: / / cdn. publicinterestnetwork . org/assets /b3ba157e28d82952 ee5b7a3f84e88499/Following-the-Money-USPIRG.pdf (retrieved December 30, 2010)

2. Berners-Lee, T.: Linked Data. International Journal on Semantic Web and Information Systems. w3c.org. (2006)

3. Bertot, J.C., Jaeger, P.T., Shuler, J.A., Simmons, S.N., Grimes, J.M.: Reconciling government documents and e-government: Government information in policy, librarianship, and education. Government Information Quarterly 26, 433-436 (2009)

4. Brito, J., Perraut, D.: Transparency And Performance In Government. North Carolina Journal Of Law \& Technology 11 N.C. J.L. \& Tech. On. 161 (2010)

5. Brito, J.: Hack, Mash, \& Peer: Crowdsourcing government transparency. The Columbia Science and Technology Law Review IX (2008)

6. Central Office of Information: Underlying data publication: guidance for public sector communicators, website managers and policy teams (2010),

http: / /coi.gov.uk/blogs/digigov/wp-content/uploads /

2010/07/TG135-Underlying-Data-Publication-v0-4.pdf

(retrieved December 30, 2010)

7. Davies, T.: Open data, democracy and public sector reform. A look at open government data use from data.gov.uk, MSc Dissertation, University of Oxford (2010)

8. Dawes, S.: Stewardship and usefulness: Policy principles for information-based transparency. Government Information Quarterly 27, 377-383 (2010)

9. Dawes, S.S., Helbig, N.: Information Strategies for Open Government: Challenges and Prospects for Deriving Public Value from Government Transparency. In: Wimmer, M.A., Chappelet, J.-L., Janssen, M., Scholl, H.J. (eds.) EGOV 2010. LNCS, vol. 6228, pp. 5060. Springer, Heidelberg (2010)

10. Dawes, S., Pardo, T.A., Cresswell, A.M.: Designing electronic government information access programs: A holistic approach. Government Information Quarterly 21, 3-23 (2004)

11. European Commission: Communication on the results of the negotiations concerning cohesion policy strategies and programmes for the programming period 2007-2013, COM, 301 final, Brussels (2008)

12. European Commission: Conclusions of the fifth report on economic, social and territorial cohesion: the future of cohesion policy. COM, 642 final, Brussels (2010) 
13. European Commission: The European eGovernment Action Plan 2011-2015 - Harnessing ICT to promote smart, sustainable \& innovative Government, COM, 743, Brussels (2010)

14. Greenacre, M.J.: Correspondence analysis in practice. Academic Press, London (1993)

15. Open Government Working Group: 8 Principles of Open Government Data (2007), http: / /www . opengovdata. org/ (retrieved December 30, 2010)

16. Robinson, D., Harlan, Y., Zeller, W., Felten, E.: Government Data and the Invisible Hand. Yale Journal of Law and Technology 11, 160 (2009)

17. W3C: Improving Access to Government through Better Use of the Web (2009), http: / / www.w3 .org/TR/2009/WD-egov-improving-20090310

(retrieved December 30, 2010) 